\title{
Nuntius Antiquus: inaugurating Classical Reception in Latin America
}

If you were to search the Humanities section of the Scientific Electronic Library Online (SciELO1 there is not a single periodical dedicated to the theme of Classical Reception among the 52 titles available in the area of Linguistics, Letters, and Arts. When we access the Portal of Periodicals Capes/MEC ${ }^{2}$ and perform a rapid search on the topic "classical reception", using commas and in Portuguese, there are only four related titles ${ }^{3}$ that show up, of which only one is specific and belongs to our scope. When we use the English expression "classical reception" in the search tool, the result jumps from four to 425 . If we reduce the scope of the search and focus only on peer-reviewed journals, that number goes down to 262 papers, of which we discarded three, because they didn't apply to our main area of investigation. ${ }^{4}$

According to the data obtained in the Portal of Periodicals Capes/MEC, there are three journals specialized in Classical Reception studies: Classical Receptions Journal (University of Oxford, first volume available online: 2009); International Journal of the Classical Tradition (Boston University, first volume available online: 1994); Reception: Texts, Readers, Audiences, History (Reception Study Society / Penn State University, first volume available online: 2008).

However, based on the searches performed on these two major databases it is possible to notice that the overwhelming majority of papers on this subject are found in a highly scattered way in non-specialized journals belonging to diverse areas of research. It is also possible to verify that this area of study is well consolidated outside of Latin America but that it is nascent on this side of the Atlantic. Additionally, in the Portal of Periodicals Capes/MEC and SciElo there is not a single Latin American journal that covers or discusses the presence of Classical Literature within the Literature of South America. Therefore, even though these publications are fundamental to the construction of a network of sources and interchanges that the studies on Reception unavoidably presuppose, 
they still keep the same scattered and dispersed character that the hermeneutics in Brazilian Reception has been suffering.

Thus we, the editors of the journal Nuntius Antiquus, decided that we will dedicate, from this issue forward, an annual publication covering the field of Classical Reception. We agreed that this has to be done exactly because of the lack of journals on this matter in South America, and also because we defend the importance of such matter for the studies of Classics in Literature. We believe that this publication will be the first journal in South America, and among the countries that speak Portuguese, to be exclusively dedicated to the vast and fecund investigation of the classical roots of our culture.

In a moment in which the studies on Classical Reception are no longer viewed as a new and uncertain discipline in other parts of the world, there should be no need to discuss its value. This field of studies appeared in the decade of the 1970s in Germany, mainly in the Universität Konstanz, with Hans Robert Jauss and Wolfgang Iser; and in the Universität Heidelberg, with Hans-Georg Gadamer. It is an interdisciplinary field that has been continuously growing currently holds an overwhelming strength in many areas of research, and continues to show an impressive capability to grow. Renowned classicists like Charles Martindale, Edith Hall, Helen Foley, James Porter, Lorna Hardwick, Konstantinos Nikoloutsos, and many others, have been approaching the Classics from a diachronic perspective, in search of trajectories that can enlighten cultural identities as well as find affinities between the ancient and modern worlds.

Generally speaking, there are overlapping and conflicting tendencies in this field of study. One tendency supports the idea that what configures a "reception of the classics" is when an author-inserted in any moment of time, and even in its own culture - receives and incorporates the influence of a text that precedes him. In this sense, even Plato can be studied as one of a list of authors that 'received' classical works, and so, he is a precursor to the study of the reception of Homer. Euripides, in his Phoenician Women, also returns, very creatively, to the theme of Aeschylus' Seven Against Thebes. There is no doubt among scholars that 
this Euripidean play is an ancient case of reception of the Theban myth. That means that in this concept the principle would be a dialogue established in a diachronic perspective between two artistic works, not necessarily literary ones, in which the most recent one resumes, innovatively, the oldest one that serves as its source. The other perspective presupposes a post-classical reception that can or cannot involve drastic cultural changes.

Therefore, we decided to follow the path chosen by Charles Martindale, who reconfigured and extended the concept of Classical Reception to a renewed, timely and eloquent Humanism. Following this course, we will differentiate the journal's scope, dividing it into two publications: Nuntius Antiquus: Philological and Nuntius Antiquus: Classical Reception. Thus the analysis of ancient texts will be developed with a more autonomous and specific character in the journal reserved to the study of Philology and Classical Literature. At the same time, we will widen our scope by adding an annual issue reserved for the study of the interchange between texts that dialogue diachronically as 'source' and 'reception'. This new publication will also amplify our view of the classics and their reception by displaying articles that deal with the continuity of the Ancient World. This continuity can be manifested in temporal, national, cartographic, political, ethnic and artistic categories, belonging to periods other than those known as classical. Here, we understand 'classical' to mean mainly, but not exclusively, Greco-Roman Antiquity and we will consider 'diachrony' as the principle behind our observations. 'Diachrony' here is to be understood as a process of reelaboration between two texts that can be observed, at first, in authors of the same literary group starting in Antiquity - Greek or Latin -, and that can, after that, be used by any number of authors from any place or culture throughout the millennia.

Another reason for us to be interested in the diversification of the studies of reception in Nuntius Antiquus, a "post-classic" journal with malleable borders, is that we intend to raise a debate about our identity and to try to map out our intellectual formation. In doing so, we also have a pragmatic reason for creating a space for reception studies to happen. There is a disproportionate amount of studies and bibliographies on the reception of antiquity coming from Europe and North America. Many 
other regions and cultural groups still have a modest position in such studies: Brazilian, Latin American, African, and Asian Literatures. In other words, all of the production of countries outside Europe and North America through the centuries, that is an immense field, has been explored in a manner that can be called "sporadic", or better, "spontaneous", even though some important studies are starting to appear (e. g., those by Bañuls Oller, Sánchez Méndez, Sanmartín Sáez for Iberoamerica, Goff, Simpson for Africa, Mee and Foley for the contemporary world in a wider sense).

This relatively unexplored field, the reception of Antiquity in Latin America, Africa, and Asia has generated a network of cultural interchanges that are still in need of a considerable amount of effort to be well known. It would be a great evil to us, the natives of these cultures of "new-old-worlds", if we were left inert, "laying in our splendid cradles", 5 without taking part in this effort. Thus, as time passes and successive adaptations, re-writings and re-creations appear all around the world, a definitive stage in the reception of the ancient is inaugurated. Some of these works can cause such an impact that they can even start to function as truly new, originals (this is for example the case of the Antigone by Anouilh to Modernity). Literary and artistic systems start to dialogue with other systems, and end up interacting, mixing and repelling each other in an unceasing movement.

This perspective is widened even more if we consider that Antiquity changes, and will always change, according to the place and the time from which the scholar, the non-specialized reader, or the artist, not bound by academic rules and procedures, engages in it. The study of the reception of Antiquity becomes so expansive that it gets harder for us to analyze. Even experienced researchers might get dizzy trying to do so.

However, we can set foot on one position: to abandon the old way of thinking about tradition as continuity, and re-think it as transgression, rupture, and novelty.

Therefore, even though we recognize the legitimacy of the argument that Plato is an example on the reception of Homer, what we want to do when we stimulate the publication of papers on Classical Reception on this side of the Atlantic goes well beyond that: we want to 
open new doors and demand diverse and new efforts of investigation. We foresee encouraging results for our project. What will be our best contribution to the Reception Studies? Is it to write another paper or book about Plato as a reader of Homer, tragedy and comedy? Certainly, this is a very useful and necessary task that will remain as the main contribution of Nuntius Antiquus: Philological. However, shouldn't our investigation on Reception - on authors that used the Greco-Roman patterns and that lived both during Late-Antiquity and during any other historical periods - focus perhaps a tad bit more on Brazilian and Portuguese Literature, and on the literatures and arts of other cultures as well, so we can establish dialogues that will build bridges among and unite people? If any of the above reasons is not enough for us to conduct this relevant project, we might still add that it has the property of attributing value to the cultural webs that unite the diverse peoples of the world. We would also like to clarify that, to us, this is not a theoretic question: to us this is a pragmatic and strategic problem, a question of convivial yearning. Hence, it is mostly because of this that we are willing to add an annual issue on "Classical Reception" to Nuntius Antiquus: we believe we are adding value to the issues and the debates on both otherness and identity.

Our project is to embrace unexplored dominions, break the confinement of academic departments and approach the many aspects of the reception of texts by diverse cultures with the new coming volumes. We will start with the cultures that speak Portuguese, our own cultures. We then intend to advance through the Spanish speaking cultures to finally extrapolate the barriers of these two languages, to reach other cultures and to identify, from the diverse ways of thinking of all these cultures, the common substratum originated in the ancient world. As a main result, we expect to gather together a collection of same-themed texts that otherwise could be lost if published in multiple journals around the world.

Our hope is to grapple themes that are dedicated to any type of artistic re-creation of a world from the past (its context and culture) transplanted in the present or in a diverse culture. We want to establish ideological and cultural similarities and differences between the Ancient and its Modern counterparts, in both an inter and trans-disciplinary way. 
Our main objective with this approach is to shed light both in Antiquity and Modernity and, by doing so, to understand a little bit more about the present realities that are around us and point out future possible pathways.

\author{
Maria de Fátima Sousa e Silva \\ Tereza Virgínia Ribeiro Barbosa
}

\title{
References:
}

SCIELO. SciELO - Scientific Eletronic Library Online, [s.d.]. Available: $<$ http://www.scielo.br/scielo.php?lng=pt $>$. Access: 7 jul. 2017.

HISTÓRICO. Portal de Periódicos Capes, [s.d.]. Available at: <http:// www-periodicos-capes-govbr.ez27.periodicos.capes.gov.br/index. php? option $=$ com_pcontent $\&$ view $=$ pcontent $\&$ alias $=$ historico\&Item $\mathrm{id}=124>$. Accesso: 7 jul. 2017.

${ }^{1} \mathrm{SciELO}$ is "an electronic library that holds a selected collection of Brazilian scientific journals. SciELO is the result of a research project by FAPESP - São Paulo Research Foundation (Fundação de Amparo à Pesquisa do Estado de São Paulo) together with BIREME - Latin American and Caribbean Centre on Health Sciences Information (Centro Latino-Americano e do Caribe de Informação em Ciências da Saúde). This project is supported since 2002 by CNPq - National Council for Scientific and Technological Development (Conselho Nacional de Desenvolvimento Científico e Tecnológico). The project's main objective is to develop a common methodology in the preparation, storage, dissemination and evaluation of the scientific production in electronic format. New journals are constantly added to the collection of the library as the project's activities progress more and more" (SCIELO, [s.d.], our translation). We offer a list of all the related journals in the end of this editorial as a source of investigation to our readers.

${ }^{2}$ Portal de Periódicos Capes/MEC. According to the text that introduces the portal, the portal's activities started in 1990, "when the Ministry of Education (MEC) created the program of libraries for Higher Education Institutions (IES). The project had the objective to consolidate graduate studies programs all over Brazil. Five years later MEC also started the Program of Aid for the Acquisition of Periodicals (PAAP - Programa de Apoio à Aquisição de Periódicos). This Program is the origins of the current electronic 
service of periodicals offered by the Coordination for the Improvement of Higher Level Personnel (Capes - Coordenação de Aperfeiçoamento de Pessoal de Nível Superior) to the Brazilian academic community. The Portal of Periodicals was officially released on November the 11th, 2000. At around the same time, digital libraries were being started, and editors were starting to digitalize their collections." [...] "In the last fourteen years the Portal has been considered as one of the fundamental tools for doing research and teaching in Brazil" (HISTÓRICO, [s.d.], our translation).

${ }^{3}$ The journal Acta Scientiarum. Language and Culture (UEM / Maringá - The State University of Maringá), 2014, volume 36, issue 1, p. 37-49 published a paper divided in two volumes, with Part I and Part II; Famecos Magazine - Midia, Culture and Technology (PUC-RS / Porto Alegre - The Pontifical Catholic University of Porto Alegre), Dec. 2008, Issue 37, p. 69=74, although the text does not deal with our subject; and, finally, one volume of the collection "Contemporary Challenges" (UNESP Editor, 2014) entitled Comunication, culture and language, which has the objective of "reflecting on the current problems on the dialogue between the academic and the scientific fields in Communication". The search was performed on the 7th of July 2017. ${ }^{4}$ Journals that published the papers selected in the search for "classical reception" in the Portal of Periodicals Capes-Mec (the journals followed by an asterisk are available in the portal):

1. Journals specialized on "Classical Reception": Classical Receptions Journal / Oxford; International Journal of the Classical Tradition; Reception: Texts, Readers, Audiences, History.

2. Journals on Classical Studies: Acta Classica; Antiquity; Classical World; Greece and Rome; Journal of Hellenic Studies; Journal of Social Archaeology; Scholia: Studies in Classical Antiquity*; Synthesis/ La Plata*; The Classical Review; Tydskrif vir Letterkunde*; Akroterion*; The Cambridge Quarterly; Journal of Roman Studies; Phi Kappa Phi Forum; Helios.

3. Journals that aren't specialized in Classical Studies: Acta Scientiarum. Language and Culture; ${ }^{*}$ American Literary Scholarship; Atlantis, revista de la Asociacio-n Espanola de Estudios Anglo-Norteamericanos; boundary; Britannia; Byron Journal; Children's Literature Association Quarterly; Common Knowledge; Comparative Drama; Comparative Literature; Comparative Literature Studies; Connotations; Cultural critique; English; English Literature in Transition; Espacio; Essays and Studies; Forum for world literature studies; Irish University Review: a journal of Irish Studies; Journal of Ecumenical Studies; Journal of Aesthetics \& Culture;* Journal of Archaeological Method and Theory; Journal of Historical Geography;Journal of International Women's Studies;Journal of Modern Literature Modern; Journal of Pan African Studies; * Journal of the History of Ideas; Medium Aevum; Melbourne Historical Journal; MELUS: Multi-Ethnic Literature 
of the U.S.; Milton Quarterly;* Modern Intellectual History; Nathaniel Hawthorne Review; Nebula; New Theatre Quarterly; Philology; Philological Quarterly; Political Theory; Screen; Seventeenth-Century News; Social Science History; Studies in English Literature; The American Historical Review; The American Indian Quarterly; The English Historical Review; The Journal of Commonwealth Literature; The Journal of English and Germanic Philology; The Historical Journal; The Review of English Studies; Thesis Eleven; Transformative Works and Cultures; Translation and Literature; Victorian Poetry; Victorian Studies; Journal of the History of Collections; Journal of Modern Greek Studies; Rhetoric \& Public Affairs; Renaissance Quarterly; Modern Language Quarterly; Commonweal; The Year's Work in English Studies; Vivlīofika.*

${ }^{5}$ The introduction of the second strophe of the Brazilian anthem starts like this: "Eternally laying in a splendid cradle", and we use this expression to convey the idea of laziness. 